US budgets

\section{End in sight?}

"The best we can hope for is to try to salvage a disaster and just make it a very bad year." This is how one Washington lobbyist last week summed up the prospects for next year's research budget as Congress continued, at the President's request, to chip away at the budget.

Since the beginning of the year, the prospects for science have changed substantially. When President Carter delivered his original request to Congress in January, he proposed a 13 per cent growth for basic research, about 3 per cent above the anticipated rate of inflation.

In March, after what the President's Science Advisor Dr Frank Press has described as the "traumatic experience" of a review designed to cut public expenditure and balance the overall budget, the increase was reduced to 8 per cent, barely enough to keep pace with inflation. Now even this figure is looking optimistic.

As far as congressional authorization committees (which approve programmes for funding) are concerned, there have been relatively few problems in meeting the President's requests for cuts and in some cases even greater cuts have been made.

Both houses of Congress have agreed on an authorization bill for the National Aeronautics and Space Administration (NASA) which, at a total of $\$ 5,600$ million, is $\$ 70$ million above the revised request for the agency. The two houses agreed in particular to restore funding for some of the long-range support programmes that had been cut earlier.

Similarly the National Science Foundation has so far done relatively well. The House of Representatives and the Senate have passed very different authorization bills, with the latter incorporating provisions for a major "women in science" programme, and this could involve some redistribution of funds within the agency. But the total in each case is at or above the Administration's \$1,074 million request.

But in the appropriations committees which decide how the federal budget is to be allocated - it is a different story. Most appropriations bills have still to be acted on; but in their determination to pare the federal budget wherever possible, several appropriations committees have taken basic research as one of their targets.

The worst affected so far has been the Department of Energy, which supports a large proportion of the physics programme. The department's request for energy research activities, trimmed slightly by authorization committees, was recommended for a 12 per cent cut.

This proposal stimulated intense lobbying by universities and research laboratories, as well as the Office of Science and Technology Policy, and when the budget was debated on the floor of the House, an amendment proposed by $\mathrm{Mr}$ Don Fuqua, chairman of the House Science and Technology Committee, to restore most of this cut was agreed by a wide margin.

Furthermore the intense effort involved in protecting the energy research budget is being taken as an indicator of the strength with which scientists will increasingly have to fight to retain their share of the budget pie in other areas as well.

As far as other agencies are concerned, no action has yet been taken by Congress on the National Institutes of Health budget, which for the most part does not require separate authorization. Congress is unlikely to cut back on the Administration's request for a 5.2 per cent increase to $\$ 3,350$ million; but neither is it likely to award the generous increase of previous years.

Some concern is being expressed about the Administration's decision to cut back heavily on the number of training grants. These may be traded in committee against the proposal to maintain at 5,000 the number of new and competing investigator-initiated research grants.

The House has authorized a total of $\$ 627$ million for basic research in the Department of Defense, and the Senate has authorized a comparable figure. This is lower than the $\$ 644$ million in the Administration's revised budget request, but still reprešnts a real growth of $8 \mathrm{per}$ cent over 1980 funding, far higher than for any other research agency. Also, for the third year in a row, the House appropriations committee has proposed cutting $\$ 30$ million allocated to a competitive grants programme to the Department of Agriculture, in favour of support for programmed research support through designated land-grant colleges. As in previous years, this is likely to be partially restored in the Senate.

Despite protests that reducing the Environmental Protection Agency's research activities will restrict its effectiveness, the House has authorized a budget 3 per cent lower than the Administration had requested for research, from $\$ 413$ million to $\$ 396$ million.

David Dickson

\section{International laboratory}

\section{Danes turn soft}

Danish biologists are preparing to make a strong recommendation to their Minister of Education next month that Denmark should continue to belong to the European Molecular Biology Laboratory in Heidelberg. Their previous report on the question of continued membership of EMBL was lukewarm, and persuaded a government advisory committee to decide that Denmark should rescind the EMBL treaty from mid-1981 (Nature, 26 June).
That report, now in circulation, recommended that EMBL should increase the number of permanent scientific posts (there is at present only one) and have fewer short-term contracts (now about 50); there should be more detailed research plans than hitherto; and EMBL should submit its plans for the next five-year period (1985-90) to Denmark in time for a "wellfounded" decision on membership.

Before then, says the report, the research councils should "consider whether it is desirable in principle that Denmark should participate in building up European laboratories in fields where the proportions of the problems and investment prevent attempts to establish national solutions or international collaboration in utilizing national laboratories" - thus implying that in fact EMBL was un-necessary.

EMBL's recruitment policy appears to be based in part on the assumption that the best molecular biologists are young, but the report concludes that these younger scientists require "a well-established environment with firm scientific traditions and with older experienced scientists" before they can achieve important results. Hence, the working party concluded, it is not possible to build up a good laboratory if nearly all the scientific staff are young postdoctoral fellows on short-term contracts.

Moreover "it must be expected that small working groups of scientists whose contracts are reviewed every three years will chiefly choose problems ensuring results within a short period, but on the other hand not offering great possibilities of all-important results".

The report also questioned the research management of EMBL, saying that "it does not appear very satisfactory that the individual working groups are not asked to submit fairly specific plans for their work and that the decision-making bodies, including among others the EMBL council, are given such a vague basis for making decisions". The research groups are also too small, the report considered, being no larger than those at national laboratories.

On the positive side, the report made special mention of the groups on data processing and the utilization of computers; this part of EMBL's activities was "very promising".

Nevertheless, it is felt strongly at EMBL that it is too soon to make a proper assessment of the laboratory's achievement. The laboratory was established in its present permanent headquarters in Heidelberg in 1978, and many of the staff were recruited then. The constitution of EMBL, modelled on that of the European sub-nuclear physics organization CERN, says that no person may apply for tenure until he or she has worked at EMBL for three years. Few have reached that position. The laboratory's director, Sir John Kendrew, says that there should be a marked increase in the number of tenured posts in a few years. 
EMBL acts as a service centre, with P3 and $\mathrm{P} 4$ laboratories, outstations using synchrotron light at Hamburg and neutrons at Grenoble, and instrumentation and computer groups at Heidelberg. So it is necessary, EMBL thinking goes, for the staff scientists concerned to pursue the most up to date lines of research, to keep them in touch with the immediate needs of the scientific community. Thus flexibility is a prime goal, and short-term contracts and small groups provide it.

The Danish meeting on EMBL towards the end of next month will consist not only of biologists. There will be representatives of the research councils for natural science, agriculture and medicine, just as there were on the original working party that produced the original report, so it is difficult to predict the outcome. However, whereas that report recommended that the government should foot the $£ 120,000$ EMBL bill, the new report may suggest that a single research council takes the subscription into its own budget. An obstacle may be that at present no Danish biologist works at EMBL, although a computer scientist and some ancillary staff do so.

Robert Walgate

\section{Scientific instruments}

\section{Nature spin-off}

The colour filters supplied with the 3 April issue of Nature have turned out to have an unexpected use. In some laboratories, it seems that the filters are superior to others on the market in the contrast they provide.

Dr R. Zeki of University College London, whose article on colour vision prompted the distribution of the set of three colour filters (Nature 284, 412-421; 1980 ), said last week that he had received a number of comments on the value of the filters, which he had passed on to Polaroid, the manufacturers.

One of those who have found the red filter of particular value is Mr David Owen, a graduate student in the laboratory of $\mathrm{Dr}$ C. Harwood, of the University of Newcastle upon Tyne. One series of experiments is to identify extra-

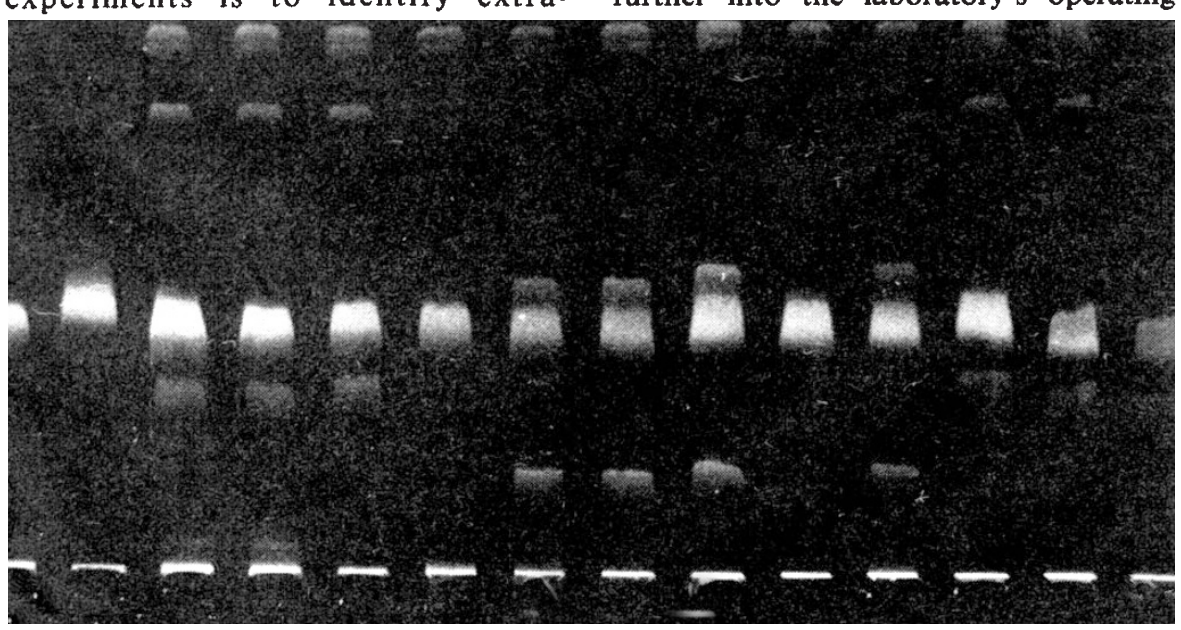

chromosomal genetic elements in bacteria. The procedure is to separate DNA molecules by gel electrophoresis and to make molecules of different classes apparent by treating the gel with a fluorescent dye that binds to DNA.

$\mathrm{Mr}$ Owen explained last week that he had had some trouble finding a suitable filter for photographing the pattern of visible light stimulated by ultraviolet radiation, so he had tried "Dr Zeki's red filter".

"To our surprise", he said, "the resulting photographs were far superior ... in that the DNA bands were clearly visible against a black background". The accompanying illustration is an example of such a photograph, in which the bright central band represents chromosomal DNA and the sidebands DNA from plasmids.

No agreed explanation of this result is available, although it seems likely that the narrowness of the transmission band of the red filter may account for the sharp contrast.

The Polarioid Corporation has apparently developed these filters largely for research purposes. A spokesman for the company said last week that filters with narrow transmission bands should be available from more conventional sources, but that the company might reconsider its decision that its filters would not be put on the market if the demand for them turned out to be sufficient.

\section{High-energy physics}

\section{Trouble ahead}

\section{Washington}

As if bleak budget prospects were not enough, high-energy physicists in the United States are facing another delicate question - what to do about continued difficulties in the development of superconducting magnets for the $400 \times 400$ $\mathrm{GeV}$ accelerator (ISABELLE) now under construction at the Brookhaven National Laboratory on Long Island.

The official line is that a substantial effort must be maintained to resolve the difficulties, even if this means cutting further into the laboratory's operating 